\title{
Qualitative Anatomical Characteristics of Compression, Lateral, and Opposite Woods in Pinus merkusii and Agathis loranthifolia
}

\author{
Byantara Darsan Purusatama ${ }^{1}$, Jong Ho Kim², Go Un Yang ${ }^{2}$, Fauzi Febrianto ${ }^{3}$, Wahyu Hidayat ${ }^{4}$, Seung \\ Hwan Lee ${ }^{2}$, and Nam Hun Kim²,* \\ ${ }^{1}$ Institute of Forest Science, Kangwon National University. Chuncheon 24341, Republic of Korea \\ ${ }^{2}$ Department of Forest Biomaterials Engineering, College of Forest and Environmental Sciences, Kangwon National University. \\ Chuncheon 24341, Republic of Korea \\ ${ }^{3}$ Department of Forest Products, Faculty of Forestry and Environment, IPB University. IPB Dramaga Campus, Bogor, 16680, \\ Indonesia \\ ${ }^{4}$ Department of Forestry, Faculty of Agriculture, University of Lampung. Jl. Sumantri Brojonegoro 1, Bandar Lampung, 35145, \\ Lampung, Indonesia \\ * Corresponding Author. E-mail address: kimnh@kangwon.ac.kr
}

\section{ARTICLE HISTORY:}

Received: 4 May 2021

Peer review completed: 20 May 2021 Received in revised form: 25 May 2021 Accepted: 30 May 2021

\section{KEYWORDS:}

Agathis

Anatomical characteristics

Reaction wood

Sumatran pine
(C) 2021 The Author(s). Published by Department of Forestry, Faculty of Agriculture, University of Lampung in collaboration with Indonesia Network for Agroforestry Education (INAFE). This is an open access article under the CC BY-NC license:

https://creativecommons.org/licenses/by$\mathrm{nc} / 4.0 /$.

\begin{abstract}
This study aimed to observe and compare the qualitative anatomical characteristics of compression (CW), lateral (LW), and opposite (OW) woods in the stem wood of Sumatran pine (Pinus merkusii) and Agathis (Agathis loranthifolia). The anatomical characteristics were observed using optical microscopy and scanning electron microscopy. CW showed a gradual transition from earlywood to latewood in both species, circular tracheid shape, many intercellular spaces, irregular tracheid tips, helical cavities, and slit-like bordered pits. CW of Sumatran pine showed an indistinct growth ring, while $\mathrm{CW}$ of Agathis showed a distinct growth ring. Helical ribs occurred only in CW of Sumatran pine. LW and OW showed an oval tracheid with an angular outline, regular tracheid arrangement, and tapered tracheid tips in both species. LW and OW showed mainly uniseriate bordered pits in Sumatran pine, while LW and OW of Agathis frequently showed multiseriate bordered pits. CW, LW, and OW showed fusiform and uniseriate rays in Sumatran pine, while those of Agathis showed uniseriate rays. In conclusion, $\mathrm{CW}$ showed distinctive qualitative anatomical characteristics to LW and OW in both species, while LW and OW mainly showed similar characteristics. In particular, there were considerably distinctive characteristics between $\mathrm{CW}$ from both species.
\end{abstract}

\section{Introduction}

Compression wood $(\mathrm{CW})$ is a reaction wood formed due to the mechanical stress of trees and restores the vertical growth (gravitropism) in the main stems or branch woods of conifers. Moreover, CW occurs on the lower side of the stem or branch wood (Barnett et al. 2014). Besides, Lateral (LW) and opposite wood (OW) also occur in a leaning stem and branch wood of reaction wood (Ruelle 2014). CW has distinctive anatomical characteristics compared to normal wood, LW, and OW. Qualitatively, CW showed helical cavities, helical ribs, round tracheid shape, thicker cell wall than normal wood, highly lignified $S_{2}$ layer, numbers of intercellular spaces, distorted bordered pits, and cross-field pits (Donaldson and Singh 2013). Quantitatively, CW had a shorter tracheid length, smaller radial diameter, lower relative crystallinity, and smaller 
crystallite width than LW and OW (Purusatama and Kim 2018; Purusatama and Kim 2020; Purusatama et al. 2020). Moreover, Wimmer and Johansson (2014) reported that CW had distinctive physical and mechanical properties to normal wood, and CW is an undesirable raw material for commercial lumber, wood-based panels, and pulp and paper manufacture.

Sumatran pine (Pinus merkusii) and Agathis (Agathis loranthifolia) woods are widely planted in Indonesian plantation forests. In addition, both species are common raw materials for lumber, wood panels, musical instruments, and pulp and paper industries (Martawijaya et al. 2005). For the anatomical characteristics, Sumatran pine wood shows window-like and pinoid pits in the cross-field, resin canals, bordered pit, and uniseriate and fusiform rays, while Agathis wood shows tracheids with resinous materials, cupressoid and taxodioid pits in the cross-field, uniseriate rays, and hexagonal bordered pit (Jang et al. 2014; Ogata et al. 2008).

There are a few studies on the anatomical characteristics of reaction wood in tropical softwood. Westing (1965) reported that the helical cavity was absent in the CW of Agathis spp. and Araucaria spp. Timell (1986) also mentioned that helical cavities were absent in CW of Agathis robusta. As reported by Pandit and Rahayu (2007), the CW of Agathis loranthifolia showed a circular shape tracheid in the transverse surface and helical cavities in the radial section. Moreover, the $\mathrm{S}_{3}$ was absent in the $\mathrm{CW}$, and the MFA in the $\mathrm{S}_{2}$ layer was distinctively greater than normal wood. Kim et al. (2015) revealed that in Agathis borneensis, mild CW showed intercellular spaces, while the rounded-shaped tracheid and helical cavities were absent. In addition, greater lignification of the outer part of the $\mathrm{S}_{2}$ layer occurred in mild CW of Agathis borneensis.

As mentioned above, Sumatran pine and Agathis are common species in the plantation forest and commercial raw materials for the wood industry in Indonesia. However, reaction wood frequently occurs in fast-growing conifers from the plantation forest, such as Agathis, Pinus, and Podocarpus, and caused many problems in the wood industry (Pandit and Rahayu 2007). However, there is still lack on the intrinsic characteristics of reaction wood in conifers from tropical wood species. Furthermore, there is still no comparative study on the anatomical characteristics of $\mathrm{CW}, \mathrm{LW}$, and $\mathrm{OW}$ from tropical wood conifers. Therefore, this study aimed to investigate and compare the qualitative anatomical characteristics of $\mathrm{CW}, \mathrm{LW}$, and $\mathrm{OW}$ in Sumatran pine and Agathis woods.

\section{Materials and Methods}

\subsection{Materials}

A tree for each Sumatran pine and Agathis was obtained from Gunung Walat IPB University Forest, Sukabumi, West Java, Indonesia $\left(6.882937^{\circ} \mathrm{N}, 106.818511^{\circ} \mathrm{E}\right)$. The basic information of the sample trees is presented in Table 1. In this study, the qualitative anatomical characteristics were investigated in the wood disc of Sumatran pine at diameter breast height (DBH) and Agathis at $3 \mathrm{~m}$ above the $\mathrm{DBH}$, which has the same diameter.

\subsection{Microscopy}

The qualitative anatomical characteristics, such as the tracheid shape and arrangement, helical cavities, helical ribs, intercellular spaces, and ray properties, were observed with optical microscopy and scanning electron microscopy. For optical microscopy, wood discs were converted to small blocks $\left(1 \mathrm{~cm}^{3}\right)$ and softened in a boiling mixture of glycerin and water (50:50). 
Thin slices with a 15-20 $\mu \mathrm{m}$ thickness were prepared using a sliding microtome (Nippon optical works Co, LTD., Tokyo, Japan). All thin slices were stained with $1 \%$ safranin solution and dehydrated by grade series of alcohol $(50 \%, 70 \%, 90 \%, 95 \%$, and 99\%) and xylene. Permanent slides were prepared with Canada balsam. For the tracheid tip observation, the CW, LW, and OW samples were soaked in Schultze reagent for three days and delignified using Franklin's method (Franklin 1945). The anatomical observation was performed with an optical microscope (Eclipse E600; Nikon, Tokyo, Japan) is connected to an image analysis system (IMT i-Solution Lite, Vancouver, Canada). For the scanning electron microscopy, the small wood blocks $\left(1 \mathrm{~cm}^{3}\right)$ of CW, LW, and OW from both species were air-dried, and the samples were coated with gold using a Cressington sputter coater (ULVAC G-50DA, Japan). The coated samples were observed under a scanning electron microscope (SEM) (JSM-5510, Japan, $15 \mathrm{kV}$ ).

Table 1. Basic information of the sample trees

\begin{tabular}{clccc}
\hline No. & \multicolumn{1}{c}{ Species } & Age & DBH & Location \\
\hline 1 & $\begin{array}{l}\text { Sumatran pine } \\
\text { (Pinus merkusii) }\end{array}$ & $\begin{array}{c}49 \\
\text { (since 1970) }\end{array}$ & $40 \mathrm{~cm}$ & $\begin{array}{c}\text { Gunung Walat IPB } \\
\text { University }\end{array}$ \\
2 & $\begin{array}{l}\text { Agathis } \\
\text { (Agathis lorantifolia) }\end{array}$ & $\begin{array}{c}65 \\
\text { (since 1954) }\end{array}$ & $89 \mathrm{~cm}$ & $\begin{array}{c}\text { West Java, Indonesia } \\
\left(6.882937^{\circ} \mathrm{N}, 106.818511^{\circ} \mathrm{E}\right)\end{array}$ \\
\hline
\end{tabular}
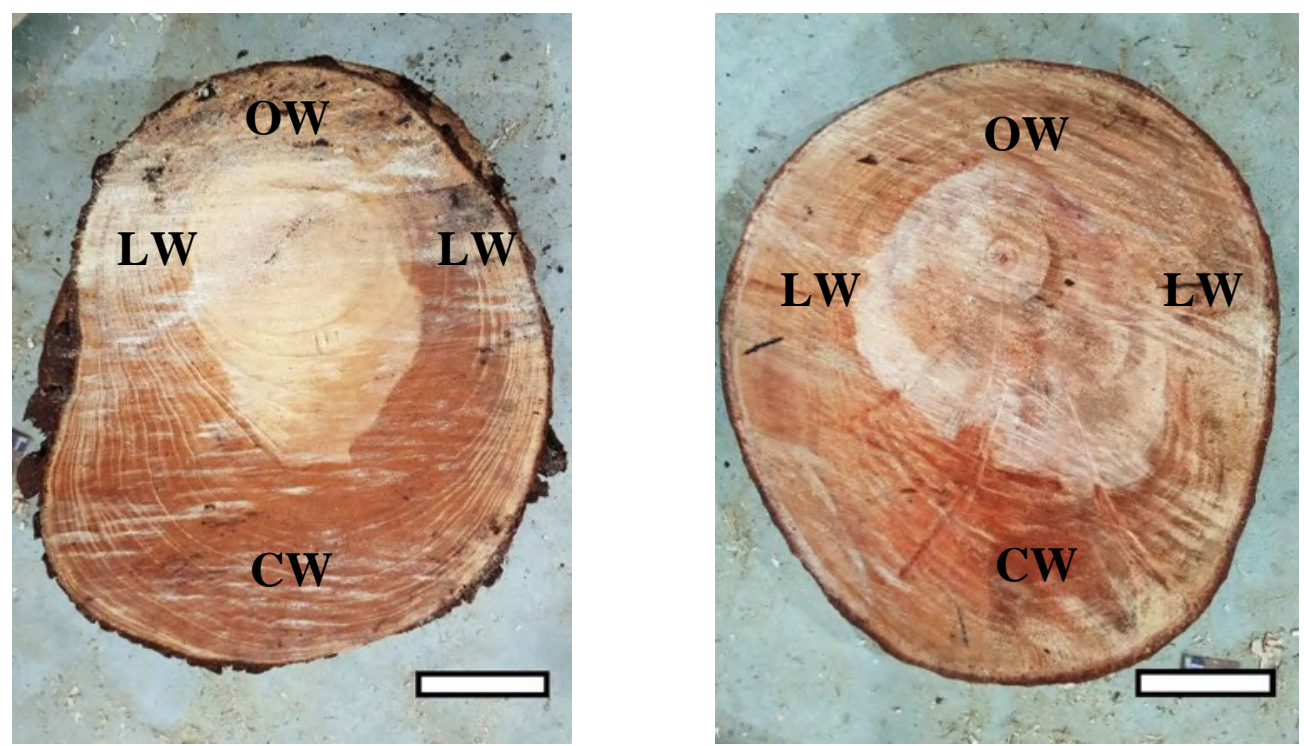

Fig. 1. A fresh cut wood discs of Pinus merkusii (left) and Agathis lorantifolia (right).

- Scale bars $=10 \mathrm{~cm}$.

\section{Results and Discussion}

3.1. Anatomical Characteristics of Compression, Lateral, and Opposite Woods in the Three Sections

\subsubsection{Cross-section}

The optical micrographs of the cross-section in CW, LW, and OW of Sumatran pine and Agathis are presented in Fig. 2. CW of Sumatran pine displayed a gradual transition from earlywood to latewood, while LW and OW showed an abrupt transition. In addition, the growth 
ring boundary was indistinct in CW, and it was distinct in LW and OW. In Agathis, CW exhibited a gradual transition from earlywood to latewood, while LW and OW showed no transition from earlywood to latewood. Furthermore, the growth ring boundary was distinct in CW, LW, and OW of Agathis. Kim et al. (2015) mentioned that mild CW exhibited indistinct growth ring boundary in A. borneensis, while normal wood displayed recognizable growth rings. Additionally, Jang et al. (2014) mentioned that $A$. loranthifolia showed a distinct growth ring boundary and no transition from earlywood to latewood. As Chung and Lee (1989) reported, CW exhibited a gradual transition from earlywood to latewood in Pinus densiflora. Eom and Butterfield (1997) described that $\mathrm{CW}$ presented a gradual transition from earlywood to latewood of Pinus radiata, while LW and OW had an abrupt transition. In addition, CW and OW showed an abrupt transition from earlywood to latewood in the stem wood of Ginkgo biloba, while LW showed gradual transition (Purusatama et al. 2018).
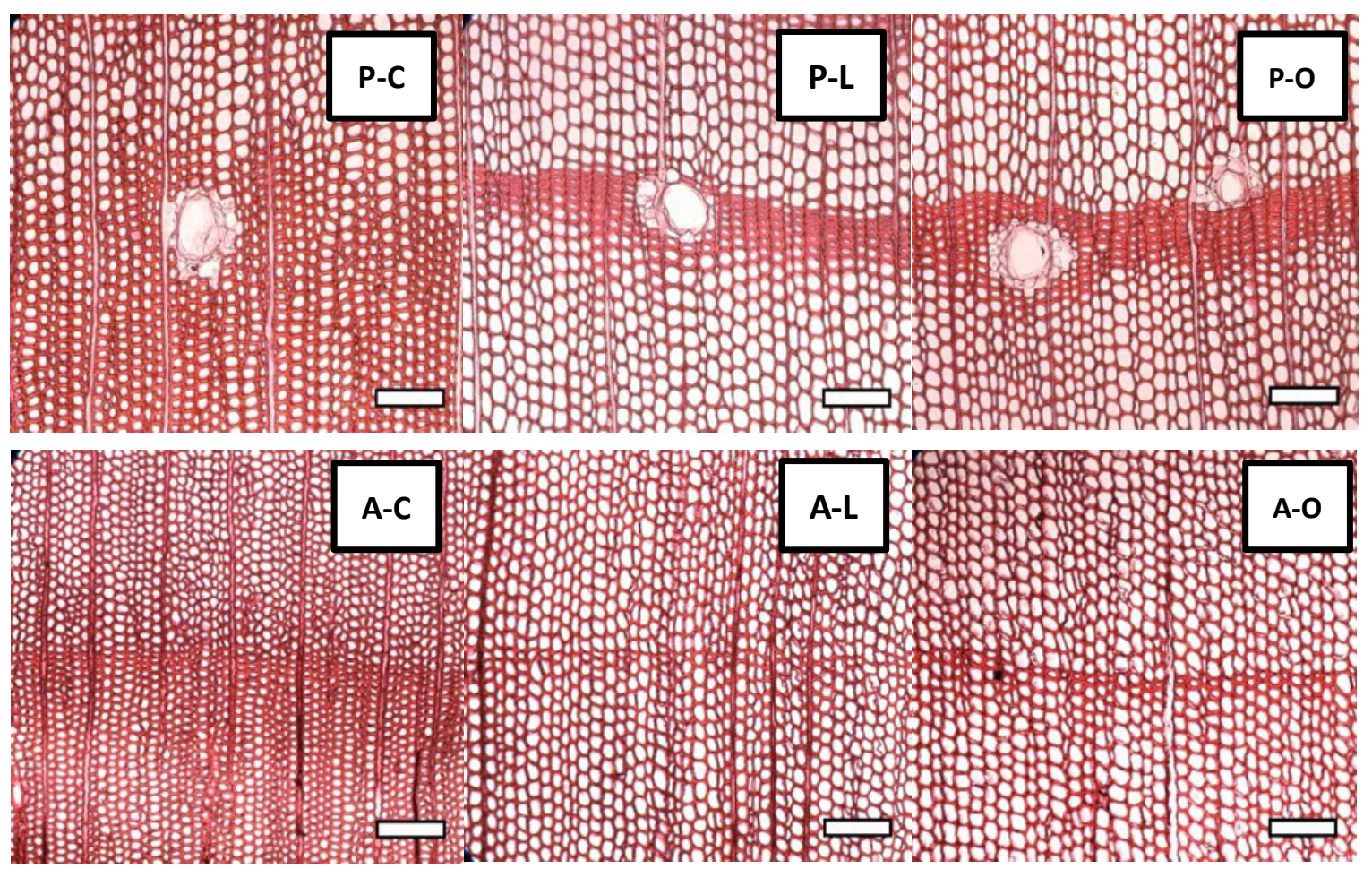

Fig. 2. Optical micrographs of the cross-section in CW, LW, and OW of Sumatran pine (P-C, P-L, and P-O) and Agathis (A-C, A-L, and A-O), respectively. - Scale bars $=200 \mu \mathrm{m}$.

The scanning electron micrographs of the cross-section in CW, LW, and OW of Sumatran pine and Agathis are presented in Fig. 3. In both species, CW showed a circular shape tracheid, helical cavities and intercellular spaces. Furthermore, LW and OW displayed oval lumen with angular outlines and no intercellular spaces in both species. As summarized by Yoshizawa et al. (1985), a round tracheid shape, intercellular spaces, and helical cavities occurred in the CW from Pinaceae and Araucariaceae. Pandit and Rahayu (2007) reported that CW showed a circular shape tracheid in the transverse surface of A. loranthifolia, while the normal wood exhibited a rectangular form. Kim et al. (2015) revealed that mild CW of A. borneensis showed a similar tracheid shape with the normal wood, and helical cavities were absent on the cross-section of mild CW. Eom and Butterfield (2001) mentioned that CW showed round outline, helical cavities, and intercellular spaces, while LW and OW showed angular to rectangular in outline in the stem wood and branch wood of New Zealand rimu. Additionally, Purusatama et al. (2018) reported that CW presented 
circular tracheids with angular outlines and many intercellular spaces in the stem wood of Ginkgo biloba, while LW and OW showed rectangular tracheids and fewer intercellular spaces.
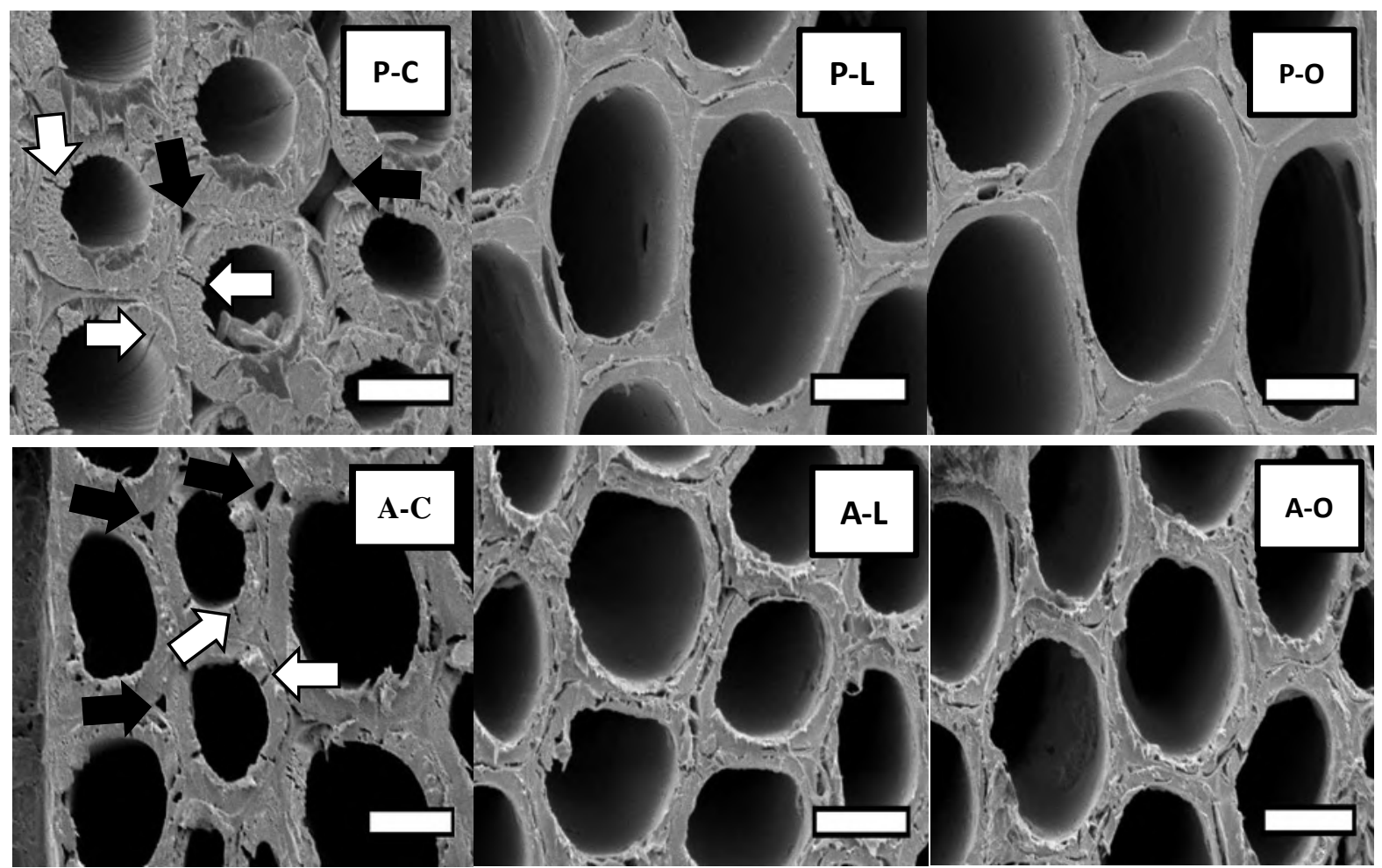

Fig. 3. Scanning electron micrographs of the cross-section in CW, LW, and OW of Sumatran pine (P-C, P-L, and P-O) and Agathis (A-C, A-L, and A-O), respectively. Helical cavities (white arrow) and intercellular spaces (black arrow) occurred in $\mathrm{CW}$ of both species.

- Scale bars $=15 \mu \mathrm{m}$.

\subsubsection{Radial section}

The optical micrographs and scanning electron micrographs of the radial section in CW, LW, and OW of Sumatran pine and Agathis are presented in Fig. 4 and Fig. 5, respectively. CW of both species showed slit-like bordered pits and irregular tracheid arrangement. Additionally, as shown in Fig. 6, CW of Sumatran pine clearly displayed helical cavities and helical ribs. In Agathis, CW showed only a few helical cavities without helical ribs. In both species, LW and OW showed a regular arrangement of tracheids in the radial section. In Sumatran pine, LW and OW showed bordered pits with mostly uniseriate and few biseriate, while LW and OW of Agathis showed commonly multiseriate (2-3 rows) bordered pits.

Yoshizawa and Idei (1987) summarized that the slit-like bordered pit, helical cavities, and helical ribs were found in CW of Pinacea, such as Abies firma, Abies sachalinensis, Cedrus deodara, Larix leptolepis, Picea abies, Picea glehnii, Picea jezoensis, Pinus pentaphylla, and Pinus densiflora. Additionally, the authors also mentioned that those characteristics also appeared in mild CW of Araucaria brasiliana. Pandit and Rahayu (2007) mentioned that CW showed helical cavities in the radial section of A. loranthifolia. As Westing (1965) reported, the helical cavity was absent in CW of Agathis spp. and Araucaria spp. Moreover, Timell (1986) also described that helical cavity was absent in $\mathrm{CW}$ of Agathis robusta. In A. borneensis, the tracheid of mild CW had intercellular spaces, while the rounded-shaped tracheid and helical cavities were absent (Kim et al. 2015). In our previous study, the radial section of CW showed an irregular 
arrangement of tracheids in earlywood, helical cavities, and slit-like bordered pit (Purusatama et al. 2018; Purusatama and Kim 2018).

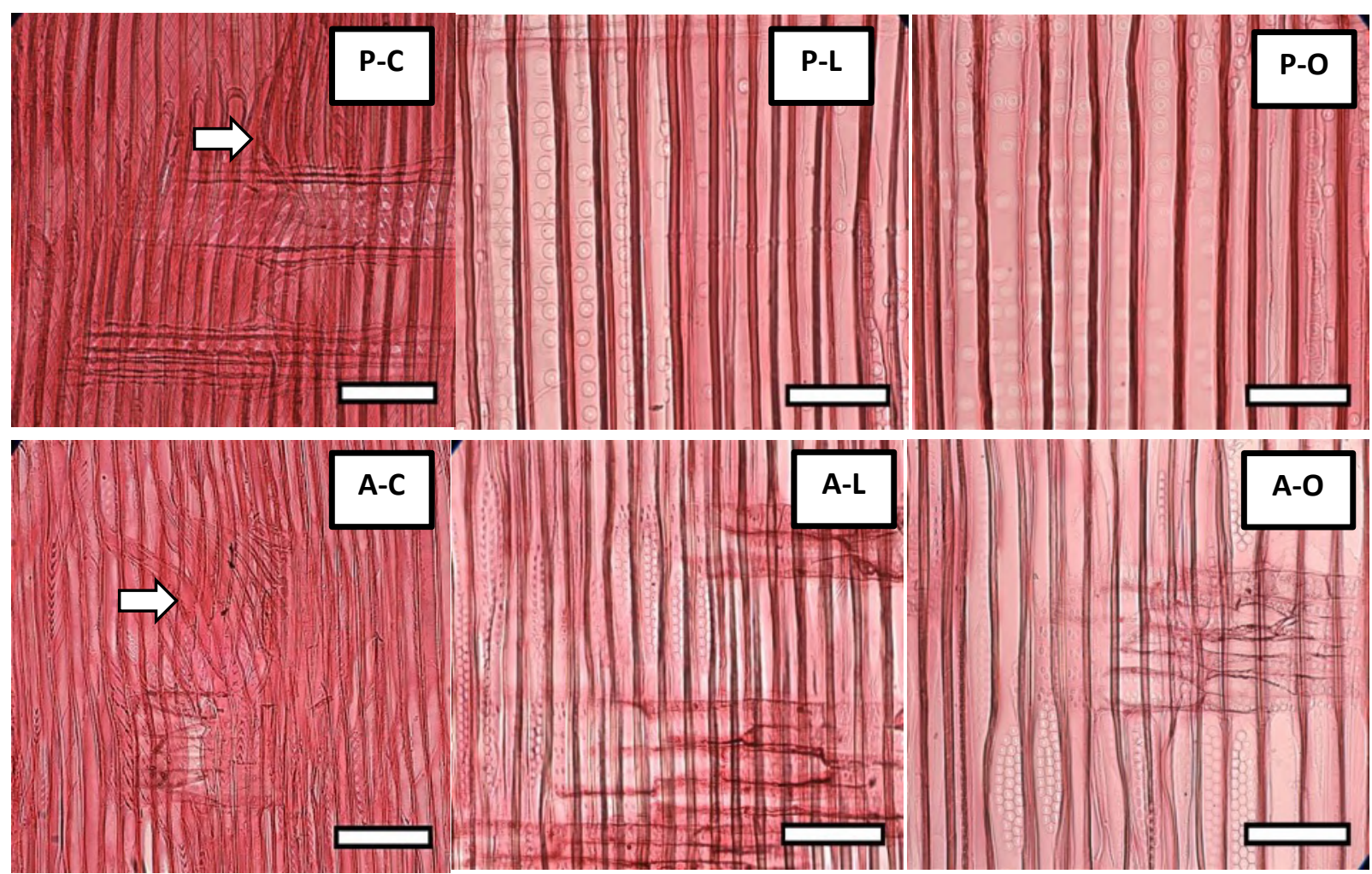

Fig. 4. Optical micrographs of the radial section in CW, LW, and OW of Sumatran pine (P-C, P-

L, and P-O) and Agathis (A-C, A-L, and A-O), respectively. The irregular arrangement of tracheid in CW (white arrow). - Scale bars $=125 \mu \mathrm{m}$.

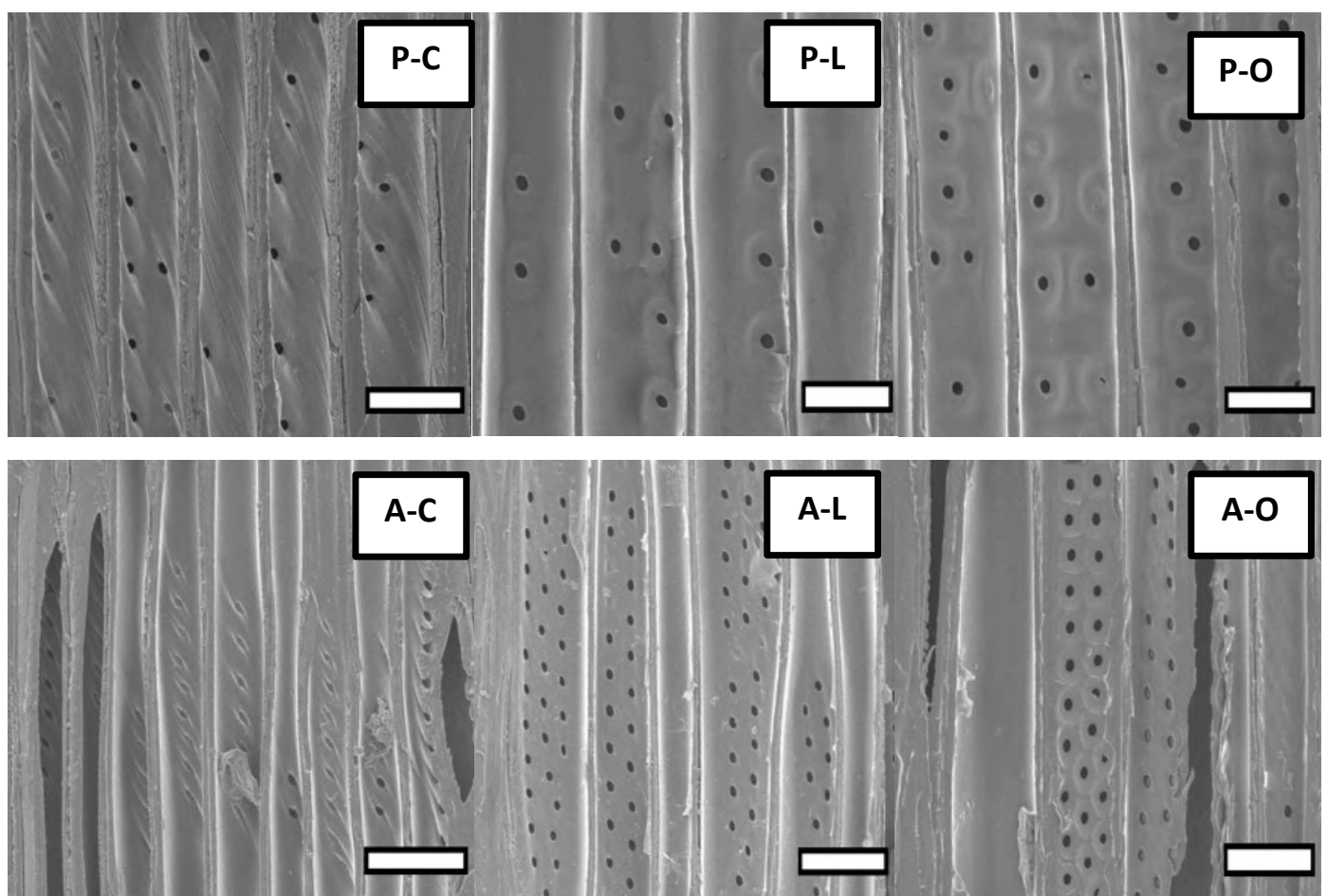

Fig. 5. Scanning electron micrographs of the radial section in CW, LW, and OW of Sumatran pine (P-C, P-L, and P-O) and Agathis (A-C, A-L, and A-O). -Scale bars $=50 \mu \mathrm{m}$. 

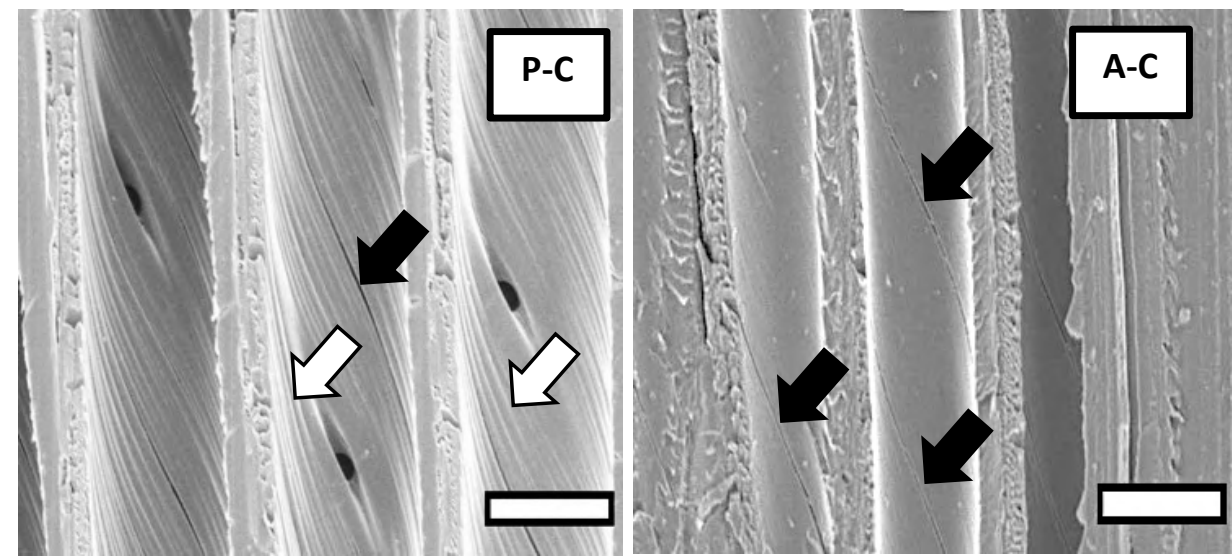

Fig. 6. Scanning electron micrographs of the radial section in CW of Sumatran pine (P-C) and Agathis (A-C). Helical ribs (white arrow) only occurred in CW of Sumatran pine and helical cavities (black arrow) in CW of both species. - Scale bars $=25 \mu \mathrm{m}$.

\subsubsection{Tangential section}

The optical micrographs of the tangential section in CW, LW, and OW of Sumatran pine and Agathis are presented in Fig. 7. In Sumatran pine, CW, LW, and OW showed uniseriate and fusiform rays. In Agathis, CW, LW, and OW showed uniseriate rays in the tangential section. Additionally, a few biseriate rays were discovered in the LW of Agathis. As shown in Fig. 8, helical cavities occurred in the tracheid wall of $\mathrm{CW}$ from both species, but the helical ribs only occurred in the CW of Sumatran pine. As Timell (1986) reported, the helical cavities occurred in the tangential wall of CW of Pinus resinosa, Larix laricina, and Pseudotsuga menziesii. Purusatama and Kim (2018) revealed that the CW of Gingko biloba showed helical cavities in the tangential section.
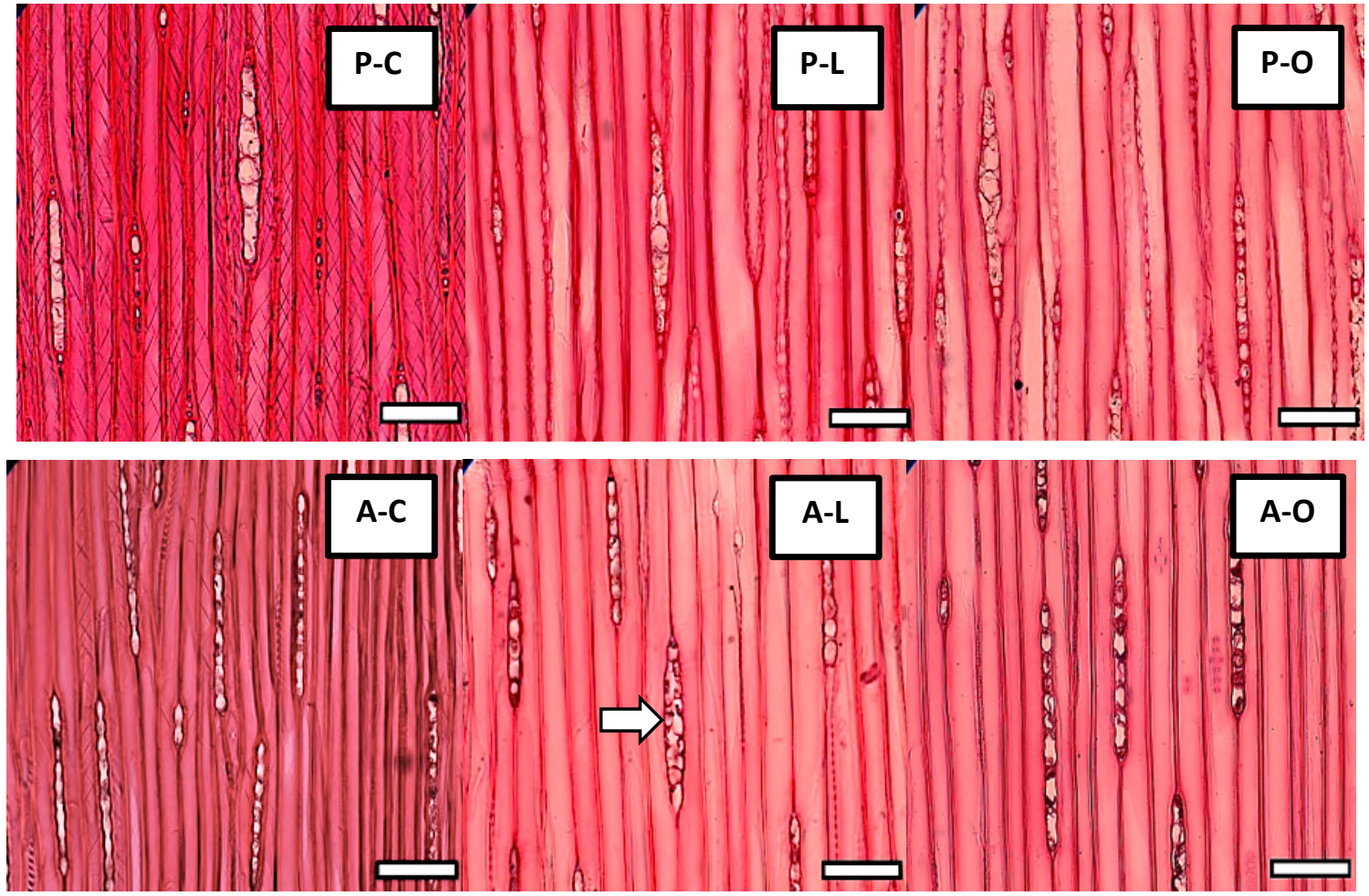

Fig. 7. Optical micrographs of the tangential section in CW, LW, and OW of Sumatran pine (PC, P-L, and P-O) and Agathis (A-C, A-L, and A-O). Biserieate ray in LW of Agathis (white arrow). - Scale bars $=125 \mu \mathrm{m}$. 

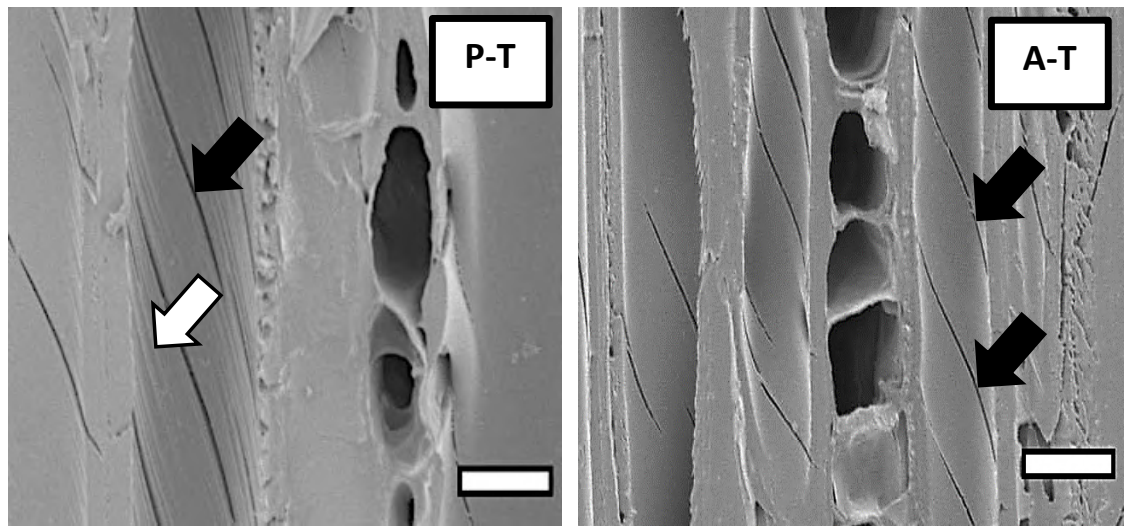

Fig. 8. Scanning electron micrographs of the tangential section in CW of Sumatran pine (P-T) and Agathis (A-T). Helical ribs (white arrow) only occurred in CW of Sumatran pine and helical cavities (black arrow) in $\mathrm{CW}$ of both species. - Scale bars $=25 \mu \mathrm{m}$.

\subsection{Tracheid tip characteristics}

The light micrographs of the tracheid tips of CW, LW, and OW in Sumatran pine and Agathis are presented in Fig. 9. CW of Sumatran pine showed a bifurcate and tapered tracheid tip with helical cavities, while LW and OW showed tapered tracheid tips. In Agathis, CW showed bifurcated tracheid tips and helical cavities, while LW and OW showed tapered tracheid tips. In our previous study, CW of Ginkgo biloba showed branched (bifurcated) tracheid tips, while LW and OW showed normal (tapered) tracheid tip (Purusatama et al. 2018). Yoshizawa et al. (1985) reported that $\mathrm{CW}$ is identical with abnormal tracheid tip types, such as flattened, bifurcated, abnormally expanded, transversely elongated, L-shaped, and locally elongated. In addition, the tapered tracheid tip commonly occurred in normal wood. Moreover, Yoshizawa et al. (1987) revealed that about $20 \%$ of the tip observed in the normal wood of Larix were abnormal, which flattened, L-shaped, and locally elongated tips were dominant.

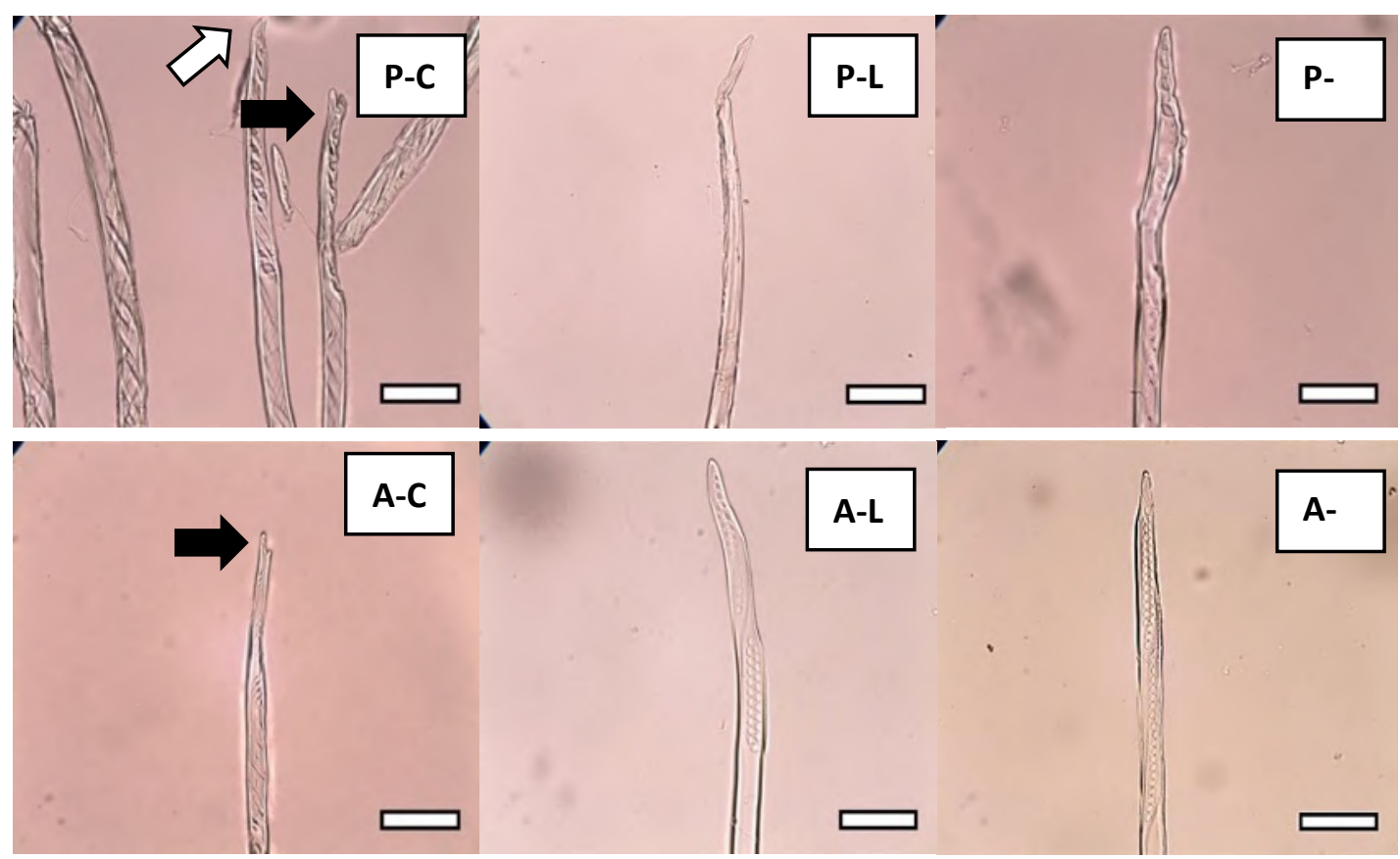

Fig. 9. Optical micrographs of the tracheid tips in CW, LW, and OW of Sumatran pine (P-C, PL, and P-O) and Agathis (A-C, A-L, and A-O). Tapered (white arrow) and bifurcated (black arrow) tracheid tips in CW.-Scale bar: $50 \mu \mathrm{m}$. 


\section{Conclusions}

Compression wood of both species showed distinctive qualitative anatomical characteristics to LW and OW, while LW and OW mainly showed similar characteristics. Furthermore, there were distinctive differences in the $\mathrm{CW}$ of both species. In the cross-section, $\mathrm{CW}$ of Sumatran pine showed an indistinct growth ring boundary, while LW and OW showed a distinct growth ring boundary. CW, LW, and OW of Agathis showed distinct growth ring boundaries. In the radial section, the CW in both species showed an irregular arrangement of tracheid and a slit-like bordered pit with helical cavities, while LW and OW comparatively regular arrangements. Additionally, the helical ribs occurred only in the CW of Sumatran pine. LW and OW of Sumatran pine displayed uniseriate and biseriate bordered pits, while LW and OW of Agathis showed multiseriate bordered pits (2-3 rows). CW, LW, and OW of Sumatran pine showed fusiform rays and uniseriate rays in the tangential section, while those of Agathis showed mainly uniseriate rays. $\mathrm{CW}$ of Sumatran pine showed bifurcated and tapered tracheid tips, while CW of Agathis showed only bifurcated tracheid tips. LW and OW in both species showed tapered tracheid tips.

\section{Acknowledgments}

This research was supported by the Science and Technology Support Program through the National Research Foundation of Korea (NRF) funded by the Ministry of Science and ICT (MSIT) (NRF-2019K1A3A9A01000018) and Basic Science Research Program through NRF funded by the Ministry of Education (NRF-2016R1D1A1B01008339; No. 2018R1A6A1A03025582).

\section{References}

Barnett, J. R., Gril, J., and Saranpää, P. 2014. Introduction. in: The Biology of Reaction Wood B. Gardiner, J. Barnett, P. Saranpää, and J. Gril, eds. Springer, New York 1-11. DOI: 10.1007/978-3-642-10814-3

Chung, Y. J., and Lee, P. W. 1989. Anatomical Studies on the Features of Rays in Compression Wood of Korean Red Pine (Pinus densiflora S. Et Z.). Journal of Korean Society of Forest Science 78(2): 119-131.

Donaldson, L. A., and Singh, A. P. 2013. Formation and Structure of Compression Wood. In: Cellular Aspects of Wood Formation J. Fromm, ed. Springer-Verlag, Hamburg 225-56. DOI: 10.1007/978-3-642-36491-4

Eom, Y. G., and Butterfield, B. G. 1997. Anatomical Comparisons of Compression, Opposite, and Lateral Woods in New Zealand Radiata Pine (Pinus radiata D. Don). Journal of the Korean Wood Science and Technology 25(2): 88-99.

Eom, Y. G., and Butterfield, B. G. 2001. Anatomical Comparison of Compression, Opposite, and Lateral Woods in New Zealand Rimu (Dacrydium cupressinum Lamb.). Journal of the Korean Wood Science and Technology 29(3):1-13.

Franklin, G. 1945. Preparation of Thin Sections of Synthetic Resins and Wood-Resin Composites, and a New Macerating Method for Wood. Nature 155: 51. DOI: 10.1038/155051a0

Kim, Y. S., Lee, K. H., and Wong, A. H. 2015. Occurrences of Mild Compression Wood in Agathis borneensis and Dacrydium elatum. IAWA Journal 36(4): 378-386. DOI: 10.1163/2294193220150108 
Jang, S. R., Jang, J. H., Kim, J. H., Febrianto, F., and Kim, N. H. 2014. Anatomical Characteristics of Major Plantation Species Growing in Indonesia II. Journal of the Korean Wood Science and Technology 42(6): 635-645. DOI: 10.5658/WOOD.2014.42.6.635

Martawijaya, A., Kartasujana, I., Kadir, K., and Prawira, S. A. 2005. Atlas Kayu Indonesia Jilid I. Pusat Penelitian dan Pengembangan Hasil Hutan, Bogor.

Ogata, K., Fujii, T., Abe, H., and Baas, P. 2008. Identification of the Timbers of Southeast Asia and the Western pacific. Kaiseisha Press 368-371.

Pandit, I. K. N., and Rahayu, I. S. 2007. Ultra-Structure of Compression Wood of Agathis (Agathis loranthifolia Salisb.) and Its Relation to Physical Properties. Jurnal Ilmu dan Teknologi Kayu Tropis 5(1): 1-6.

Purusatama, B. D., Kim, Y. K., Jeon, W. S., Lee, J. A., Kim, A. R., and Kim, N. H. 2018. Qualitative Anatomical Characteristics of Compression Wood, Lateral Wood, and Opposite Wood in a Stem of Ginkgo biloba L. Journal of the Korean Wood Science and Technology 46(2): 125-131. DOI: 10.5658/WOOD.2018.46.2.125

Purusatama, B. D., and Kim, N. H. 2018. Quantitative Anatomical Characteristics of Compression Wood, Lateral Wood, and Opposite Wood in the Stem Wood of Ginkgo biloba L. BioResources 13(4): 8076-8088. DOI: 10.15376/biores.13.4.8076-8088

Purusatama, B. D., and Kim, N. H. 2020. Cross-field Pitting Characteristics of Compression, Lateral, and Opposite Wood in the Stem Wood of Ginkgo biloba and Pinus densiflora. IAWA Journal 41(1): 48-60. DOI: 10.1163/22941932-00002107

Purusatama, B. D., Choi, J. K., Lee, S. H., and Kim, N. H. 2020. Microfibril Angle, Crystalline Characteristics, and Chemical Compounds of Reaction Wood in Stem Wood of Pinus densiflora. Wood Science and Technology 54:123-137. DOI: 10.1007/s00226-019-01140-W

Ruelle, J. 2014. Morphology, Anatomy and Ultrastructure of Reaction Wood. In: The Biology of Reaction Wood B. Gardiner, J. Barnett, P. Saranpää, and J. Gril, eds. Springer, New York 13-35. DOI: 10.1007/978-3-642-10814-3

Timell, T. E. 1986. Compression Wood in Gymnosperms (Vol. 1-3). Springer-Verlag, Berlin, Germany. DOI: 10.1163/22941932-90001077

Westing, A. H. 1965. Formation and Function of Compression Wood in Gymnosperms. Botanical Review 31: 381-480. DOI: 10.1007/BF02859131

Wimmer, R., and Johansson, M. 2014. Effects of Reaction Wood on the Performance of Wood and Wood-Based Products. In: The Biology of Reaction Wood B. Gardiner, J. Barnett, P. Saranpää, and J. Gril, eds. Springer, New York 225-248. DOI: 10.1007/978-3-642-108143_8

Yoshizawa, N., Matsumoto, S. and Idei, T. 1985. Morphological Features of Tracheid Tips Associated with Compression Wood Formation in Larix Leptolepis Gord. IAWA Journal 6(3): 245-253. DOI: 10.1163/22941932-90000945

Yoshizawa, N. and Idei, T. 1987. Some Structural and Evolutionary Aspects of Compression Wood Tracheids. Wood and Fiber Science 19(4): 343-352.

Yoshizawa, N., Kiyomiya, M., and Idei, T. 1987. Variations in Tracheid Length and Morphological Changes in Tracheid Tips Associated with the Development of Compression Wood. Wood Science and Technology 21(1): 1-10. DOI: 10.1007/BF00349713 